\section{The shaken infant syndrome}

\section{Shaking alone may not be responsible for damage}

EDITOR,-It is good to be reminded by Helen Carty and Jane Ratcliffe of the need to recognise intentional injury as a cause of morbidity and mortality among infants. ${ }^{1}$ It is dissatisfying, however, to find that this reminder is based on "shaking"-an ill defined action whose sequelae do not seem to be as firmly established in the literature as the authors would have us believe.

I am surprised that the authors make no reference to the work of Duhaime $e t$ al, which raises the question of whether the forces generated by shaking alone are sufficient to cause brain damage. ${ }^{2}$ Also surprising is the authors' use of language in describing the violence of the act of shaking: the phrase "a recent description" raises hopes of an objective account by an unbiased witness, but on studying the cited reference ${ }^{3}$ one finds only an unsubstantiated statement of belief that describes "the act of shaking/slamming"-a description of an act with an element of blunt impact. The difficulty, if not impossibility, of excluding blunt impact is acknowledged by the increasing use of the term "shaken impact syndrome,"4 and both the paper by Hadley et $a \vec{F}$ (cited by Carty and Ratcliffe) and related comments acknowledge that their data do not conclusively show the potential for severe neurological trauma from shaking alone. Such lack of precision in citation does not accord with the tenor of recent judicial comment on the burden of responsibility placed on expert witnesses in cases of child abuse. ${ }^{\circ}$

Such criticism cannot be regarded as entirely pedantic in the context of raising public awareness of dangers: it raises two important questions. Firstly, what precisely are the dangers of what precise action? The descriptions of shaking vary widely so that some element of shaking could be said to occur in virtually any example of violent handling of an infant. The extent to which this element of the inflicted trauma is responsible for the injuries sustained is unclear, particularly given the substantial increase in deceleration forces resulting from impact against even padded surfaces. ${ }^{2}$ Secondly, to whom should warnings be addressed? Is a parent who is so stressed by a child's crying that he or she resorts to an act "so violent that neutral observers would recognise it as dangerous"' likely to remember or heed such warnings? Will a warning against an unwitting parental action of lesser violence have an effect on

\section{Advice to authors}

We prefer short letters that relate to a recently published article and we are unlikely to publish letters longer than $\mathbf{4 0 0}$ words and containing over five references. Letters may be shortened. Your letters should be typed with double spacing and include a word count. All authors need to sign the letter and provide one current appointment and address. We encourage you to declare any conflict of interest. Please enclose a stamped addressed envelope if you require an acknowledgment. paediatric morbidity and mortality? The need for an evaluation of such questions is acknowledged by the American Academy of Pediatrics' committee on child abuse and neglect.

It seems premature to warn against an act of violence when its precise mechanism of action is not clearly defined, its potential for serious trauma in the absence of concomitant impact is not supported by existing experimental data, and the clinical findings said to result from it are not in themselves specific.

STEPHEN LEADBEATTER Senior lecturer RYK JAMES Senior registrar SUSAN CLAYDON Senior lecturer BERNARD KNIGHT

Wales Institute of Forensic Medicine, Professor

Royal Infirmary,

Cardiff CF2 1SZ

1 Carty H, Ratcliffe J. The shaken infant syndrome. $B M \mathcal{F}$ 1995;310:344-5. (11 February.)

2 Duhaime A-C, Gennarelli TA, Thibault LE, Bruce DA, Margulies SS, Wiser R. The shaken baby syndrome. A clinical, pathological, and biomechanical study. I Neurosurg 1987;66: 409-15.

3 American Academy of Pediatrics Committee on Child Abuse and Neglect. Shaken baby syndrome: inflicted cerebral trauma. Pediatrics 1993;93:872-5.

4 Bruce DA, Zimmerman RA. Shaken impact syndrome. Pediatr Ann 1989;18:482-94.

5 Hadley MN, Sonntag VKH, Rekate HL, Murphy A. The infant whiplash-shake injury syndrome: a clinical and pathological study. Neurosurgery 1989;24:536-40.

6 re AB (a minor) (medical issues: expert evidence). Times Law Repors 1994 Aug 17.

\section{Deal with minor episodes of abuse to prevent more serious injuries}

EDIToR,-Helen Carty and Jane Ratcliffe are right to highlight the seriousness of shaking babies and the consequences of death and severe handicap. ${ }^{1}$ We believe, however, that it would be unfortunate if their work took attention away from the background of abuse in many of these children. Many of the babies have associated injuries typical of abuse, such as posterior fractures of the ribs. We have been asked our opinions on 10 children over the past three years. Eight of them had associated injuries typical of abuse. Dealing with minor episodes of abuse in babies is vital in preventing more serious injuries.

We are also concerned that too much reliance may be placed on a leaflet aimed at preventing these injuries. Carty and Ratcliffe quote the report of the "Don't shake the baby" programme in Ohio in $1989-90^{2}$ to support use of a leaflet. The author of that report based her evaluation on a $21 \%$ response rate to a questionnaire that assessed whether parents found the leaflet helpful. The respondents were likely to be a highly selected group of motivated parents and unlikely to be parents who might shake a baby. All the evidence suggests that these approaches are ineffective in preventing injuries unless undertaken on a one to one basis or through a safe community approach. ${ }^{3}$

ALISON M KEMP Senior lecturer in community child health JO SIBERT

Professor of community child health

University Department of Child Health

University of Wales College of Medicine,

Community Health Unit, Lansdowne Hospital,

Cardiff CF1 8UL
1 Carty H, Ratcliffe J. The shaken infant syndrome. BMF 1995;310:344-5. (11 February.)

Showers J. "Don't shake the baby": the effectiveness of prevention program. Child Abuse Negl 1992;16:11-8.

3 Sibert JR. Accidents to children: the doctor's role: education or environmental change. Anch Dis Child 1991;66:890-4.

\section{Serious effects of shaking were described} in 1971

EDrroR,-I am disappointed that Helen Carty and Jane Ratcliffe wrongly give priority to the late John Caffey for recognising the potentially serious effects of shaking babies.' Caffey was the first to implicate parental violence in the aetiology of infantile subdural haematoma associated with fractures of the skull and long bones, and for that his fame is secure. But the first mention of shaking of infants as a cause of subdural haematoma appeared in the $B M F$ in a paper that I wrote almost a year before Caffey's paper was published. ${ }^{2}$

Unlike Caffey, I never believed that such shaking was playful; rather, I suggested that it was thought of as a socially more acceptable form of correction than a beating, and I referred to a paper by Court in which she told of a mother confessing to shaking her baby "in an insane rage." I also noted how infants' big heads and relatively weak neck muscles, to which the editorial refers, made them particularly liable to sustain brain injury under these circumstances.

A NORMA GUTHKELCH

6A Saint John's Road, Retired professor of neurosurgery

Cambridge,

MA 02138, USA

1 Carty $H$, Ratcliffe J. The shaken infant syndrome. $B M$ 1995;310:344-5. (11 February.)

2 Guthkelch AN. Infantile subdural haematoma and its relationship to whiplash injuries. BMF 1971;ii:430-1.

\section{Authors' reply}

EDrToR,-We wish to respond first to Stephen Leadbetter and colleagues. Our editorial was written to highlight the dangers of shaking and not to enter into a review of the literature on the role of shaking versus impact in causing the often fatal and frequently devastating brain injury suffered by these infants. We are familiar with the work of Duhaime et al and the model of trauma due to impact that they describe, ${ }^{1}$ but work in primates suggests that shaking with rotation is the critical factor. ${ }^{23}$ We do not dispute that impact trauma is a factor in many cases. Perpetrators who have admitted shaking do not necessarily describe impact injuries. In such circumstances, we consider it unlikely that they would withhold information about impact. This is both our personal experience and well documented. ${ }^{4}$ The comments about lack of precision in citing references are inaccurate.

We support Alison $M$ Kemp and Jo Sibert's statement about dealing with minor episodes of abuse to prevent more serious injuries. In 15 shaken infants who required management in the intensive care unit in our hospital over four years (of whom seven died), 10 had associated injuries typical of abuse. In all 15 infants, however, the admission to the intensive care unit was the firs occasion when concerns about the family had been recognised.

We also agree that a publicity campaign about the dangers of shaking is only one aspect of preventing these appalling injuries. The educa- 